\title{
Genetic variants in interleukin-6 modified risk of obstructive sleep apnea syndrome
}

\author{
XIUQIN ZHANG $^{1 *}$, RENG-YUN LIU ${ }^{2 *}$, ZHE LEI $^{2 *}$, YEHAN ZHU $^{1}$, JIAN-AN HUANG $^{1}$, XIEFANG JIANG $^{2}$, \\ ZEYI LIU ${ }^{2}$, XIA LIU ${ }^{2}$, XIAOBEI PENG ${ }^{2}$, HUACHENG HU ${ }^{3}$ and HONG-TAO ZHANG ${ }^{2}$ \\ ${ }^{1}$ Department of Respiratory Medicine, The First Affiliated Hospital; ${ }^{2}$ Laboratory of Medical Genetics, School of Basic \\ Medicine and Biological Sciences; ${ }^{3}$ Department of Respiratory Medicine, The Second Affiliated Hospital, \\ Medical College of Soochow University, Suzhou, P.R. China
}

Received December 3, 2008; Accepted February 4, 2009

DOI: 10.3892/ijmm_00000155

\begin{abstract}
Obesity and inflammation are known to correlate with the pathogenesis of obstructive sleep apnea syndrome (OSAS). Interleukin (IL)-6, an important regulator of obesity and inflammation, was reported to phenotypically increase in patients with OSAS. This study aimed to investigate whether genetic variants in $I L-6$ confer susceptibility to OSAS. The study population consisted of 151 patients with OSAS and 75 healthy controls from Southeast China. Five haplotype-tagging single nucleotide polymorphisms (tSNPs) were selected across $21 \mathrm{~kb}$ of the $I L-6$ locus using Haploview software V4.1. The tSNPs were amplified by polymerase chain reaction (PCR) and genotyped by restriction enzyme digestion followed by gel electrophoresis. Linkage disequilibrium (LD) and haplotype reconstruction were carried out by means of a SHEsis program. No distribution difference of any of the five tSNPs between OSAS patients and controls was observed. However, in nonobese individuals $(n=117)$, the minor allele $G$ (rs1800796) decreased risk of OSAS compared with the major allele C [odds ratio (OR), 0.48; 95\% confidence interval (CI), 0.26$0.86 ; \mathrm{p}=0.014]$, and the haplotype TG (rs1880242, rs1800796) conferred a significantly decreased risk of OSAS than single allele G (rs1800796) (OR, 0.39; 95\% CI, 0.20-0.74; p=0.003). Moreover, the severity of sleep-disordered breathing (measured by apnea hypopnea index) increased linearly in carriers of the C variant of $I L-6-572 \mathrm{G} / \mathrm{C}$ polymorphism $(14.3 \pm 5.1,22.0 \pm 3.6$ and $34.8 \pm 3.5$ for $\mathrm{GG}, \mathrm{CG}$ and $\mathrm{CC}$, respectively; $\mathrm{p}=0.012$ ). To
\end{abstract}

Correspondence to: Dr Hong-Tao Zhang, Laboratory of Medical Genetics, School of Basic Medicine and Biological Sciences, Medical College of Soochow University, 199 Reníai Road, Sino-Singapore Industrial Park, Suzhou 215123, P.R. China

E-mail: htzhang@suda.edu.cn

${ }^{*}$ Contributed equally

Key words: haplotype, interleukin-6, obesity, polymorphism, sleep apnea the best of our knowledge, this is the first study to suggest that genetic variants in $I L-6$ could modify OSAS susceptibility. SNP genotyping of $I L-6$ is a potential strategy for detecting the risk of breathing disordered diseases in non-obese individuals.

\section{Introduction}

Obstructive sleep apnea syndrome (OSAS) is defined as repeated episodes of obstructive apnea and hypopnea during sleep, together with daytime excessive sleepiness or altered cardiopulmonary function $(1,2)$. OSAS has emerged as a major public health problem with the middle-aged population and obesity epidemic (3). Obesity is a strong risk factor for OSAS, and it is hypothesized that genetic variants predisposed to obesity facilitate the development of OSAS (4). Furthermore, the inflammatory process is activated in the pathogenesis of OSAS. Polymorphisms of several inflammation-associated genes, including angiotensin converting enzyme gene (ACE) (5), tumor necrosis factor-alpha gene (TNF- $\alpha)(6)$, and insulin receptor substrate gene (IRS) (7), correlate with OSAS, suggesting that inflammation is also implicated in the pathogenesis of this complex syndrome.

Interleukin-6 (IL-6), produced by many different kinds of cells in the body, is one of the most important mediators of inflammatory response (8), and plays either a pro- or antiinflammatory role (9). There are increasing experimental data showing that three SNPs $-174 \mathrm{G} / \mathrm{C}$ (rs1800795), $-572 \mathrm{C} / \mathrm{G}$ (rs1800796) and -6331T/C (rs10499563) and several haplotypes of the $I L-6$ gene are not only related to levels of plasma $I L-6$ but also to inflammation (10-14). Moreover, the $I L-6$ gene polymorphism is suggested to participate in the pathogenesis of obesity and modify the risk of developing obesity-related metabolic disorders, especially insulin resistance $(15,16)$. Herein, genetic variants in the $I L-6$ gene play an important role in the pathogenesis of OSAS. However, the IL-6 gene is not genetically associated with OSAS.

Considering the notion that association studies based on haplotypes instead of genotypes, significantly improves the power of mapping and characterizing disease-causing genes (17). We hypothesized that genetic variants in $I L-6$, comprised of polymorphisms and haplotypes, confer susceptibility to OSAS. Therefore, we employed linkage disequilibrium (LD) 
and haplotype-based analyses to address the hypothesis using five tagging SNPs (tSNPs) selected from across $21 \mathrm{~kb}$ of the $I L-6$ locus and haplotypes reconstructed with the tSNPs in 226 participants of the Han Chinese population. As a result, our data suggest that genetic variants in $I L-6$ play important roles in modifying the susceptibility to OSAS.

\section{Materials and methods}

Subjects. One-hundred and fifty-one patients with OSAS and 75 age-matched controls were enrolled after informed consent from unrelated, ethnic Han Chinese subjects. Patients were recruited from the Department of Respiratory Medicine at the First Affiliated Hospital of Soochow University between July 2005 and November 2007. Controls were sleep disorderfree individuals that were enrolled in the same region. All subjects received an examination of standard overnight polysomnography (PSG) before they were classified into case and control groups, according to the criteria of Riha (6) regarding apnea hypopnea index (AHI). All the subjects were classified into two sub-groups according to a body mass index (BMI) cut-off point of $27 \mathrm{~kg} / \mathrm{m}^{2}(18)$, obese group [BMI $\geq 27$, including OSAS patients $(\mathrm{n}=90)$ and controls $(\mathrm{n}=19)]$ and non-obese group [BMI $<27$, including OSAS patients $(\mathrm{n}=61)$ and controls $(n=56)]$. This study was approved by the ethics committee at the participating institution and the Academic Advisory Board of Soochow University.

Polysomnography. Physiological examinations of all the subjects were recorded with overnight PSG (Rembrandt Monet-32, Medcare Inc, Reykjavik, Iceland). Electroencephalography, electromyography, electrocardiography and electrooculography were performed with surface electrodes. Ventilatory movements of chest and abdomen were monitored using inductive plethysmography. Nasal and oral airflow were explored with thermistors. Arterial oxygen saturation $\left(\mathrm{SaO}_{2}\right)$ was measured by finger pulse oximetry. Apnea was defined as continuous cessation of airflow for more than $10 \mathrm{sec}$ while hypopnea was referred to as at least $50 \%$ of reduction in flow for more than $10 \mathrm{sec}$ with oxygen desaturation of $\geq 4 \%$. AHI was calculated as the total number of apneas and hypopneas per hour of sleep.

Tagging SNPs selection. HapMap SNP database (www. hapmap.org) and National Center for Biotechnology Information database (www.ncbi.nlm.nih.gov/dbSNP) were used to explore SNPs among the Han Chinese population. Twenty-four SNPs were obtained from $11 \mathrm{~kb}$ upstream of the transcriptional start site to $5 \mathrm{~kb}$ downstream of the $I L-63$ 'UTR. Minor allele frequency (MAF) $>0.05$ was allocated for capturing the entire common SNPs. The tSNPs were selected using Haploview software V4.1 on the basis of their pairwise LD with the $\mathrm{r}^{2}$ threshold of 0.8 . Of 14 frequently identified SNPs, five tSNPs (Fig. 1) that represent all the common SNPs in the $I L-6$ region were selected for association study.

Genotyping. Genomic DNA was isolated from blood samples according to standard proteinase $\mathrm{K}$ digestion and phenolchloroform extraction (19). Five tSNPs of the $I L-6$ gene were amplified by polymerase chain reaction (PCR). Primer sequence sets and various annealing temperatures for PCR are given in Table I. Each PCR was carrried out in a total volume of $25 \mu \mathrm{l}$ containing 50-100 ng genomic DNA, 1 unit Ex Taq DNA polymerase (Takara, Japan), $0.2 \mu \mathrm{mol} / 1$ of each primer, $1 \mathrm{x}$ Ex Taq Buffer ( $\mathrm{Mg}^{2+}$ Plus) and $0.25 \mathrm{mmol} / \mathrm{l}$ of each dNTP. The tSNPs were screened through restriction fragment length polymorphism with restriction endonucleases (Table I). Genotyping was done using $12 \%$ polyacrylamide gel electrophoresis followed by visualization with ethidium bromide.

LD and haplotype analysis. Lewontin coefficient (D') and squared correlation coefficient $\left(\mathrm{r}^{2}\right)$ for pairwise LD of the five tSNPs were calculated with a SHEsis program (20). Reconstructing haplotypes with the genotyping data was performed using a Full-Precise-Iteration algorithm of SHEsis, given that haplotypes with a frequency of $<0.05$ were not considered in the analysis.

Statistical analysis. Results are presented as mean $\pm \mathrm{SE}$. Comparisons between groups were performed with independent $t$ or ANOVA tests for continuous variables. Statistical analyses for genetics were applied to differentiate distribution of frequency for genotypes, alleles and haplotypes between OSAS patients and controls. Hardy-Weinberg equilibrium (HWE) analysis for genotype distribution in controls, was carried out by a Pearson's goodness-of-fit Chisquare test. Difference of genotype and allele frequencies between cases and controls were determined using Chi-square test or Fisher's exact test. Logistic regression was performed to assess odds ratios (OR) and 95\% confidence intervals (CI), which were adjusted for gender, age and BMI. All the statistical analyses above were implemented with SPSS 16.0 for Windows (SPSS Inc, Chicago, IL). Haplotype distribution difference between cases and controls was analyzed using SHEsis program. All statistical analyses are for two-sided tests, and considered significant at $\mathrm{p}<0.05$.

\section{Results}

Characteristics of OSAS and control subjects. The characteristics of 151 patients with OSAS and 75 healthy controls are shown in Table II. BMI and polysomnographic parameters of OSAS patients were significantly higher than those of controls, respectively $(\mathrm{p}<0.001)$. Compared to normal weight, overweight and obesity conferred 2.94 -fold (95\% CI, 1.00-8.64) and 9.09-fold (95\% CI, 3.07-26.92) increased risk of OSAS, respectively (Table III). This suggests that BMI increment is positively associated with increased risk of OSAS. In total, obese individuals (BMI $\geq 27$ ) had a 3.84 -fold $(95 \%$ CI, 2.02-7.29) increased risk of OSAS compared to the nonobese (BMI <27), including the normal and the overweight.

Frequency distributions for genotype and allele. Frequency distributions for all genotypes of five SNPs were not deviated from HWE in controls (data not shown). No distribution difference of genotypes or alleles between 151 patients with OSAS and 75 healthy controls was found (Table IV). After stratifying by BMI, we did not find the significant difference between obese OSAS patients and obese controls. However, the frequency of $I L-6-572 \mathrm{G}$ (rs1800796) was remarkably 

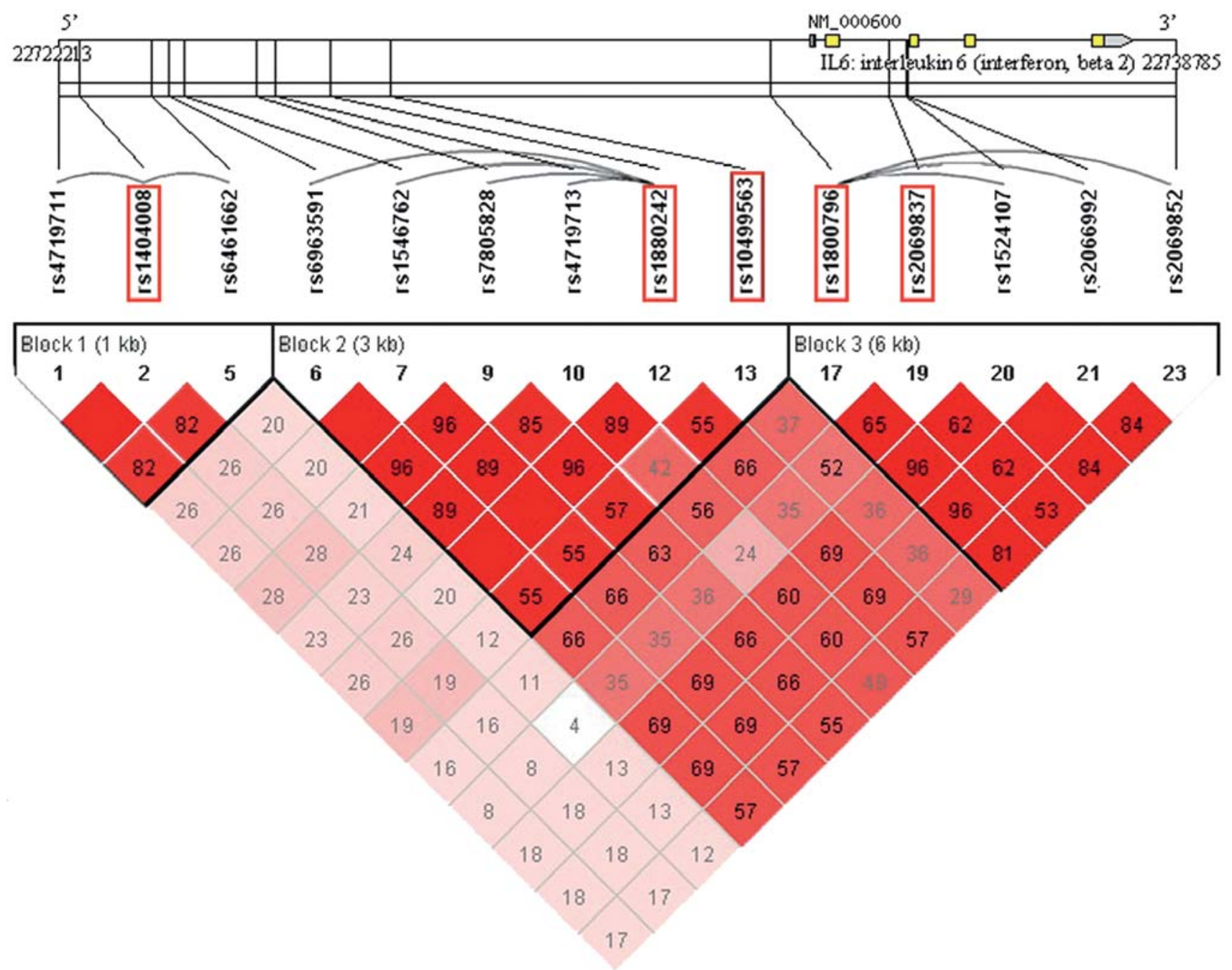

Figure 1. LD plot and tSNPs of $I L-6$. LD map of $I L-6$ gene region (from $22722 \mathrm{~kb}$ to $22743 \mathrm{~kb}$ ) was depicted using $14 \mathrm{kommon}$ SNPs (MAF >0.05) from CHB SNPs in HapMap database. The plot was generated using Haploview 4.1 with the $\mathrm{D}^{\prime}$ Color Scheme $\left(\mathrm{D}^{\prime}=0,0<\mathrm{D}^{\prime}<1\right.$ and $\mathrm{D}^{\prime}=1$ were shown by white, shades of pink and red, respectively) and pairwise $\mathrm{r}^{2}$ values were shown in diamonds. Five tSNPs were selected from three separate blocks and were labeled with a red rectangle.

Table I. Primers and restriction endonucleases used for genotyping IL-6 gene.

\begin{tabular}{|c|c|c|c|c|c|c|}
\hline \multirow[b]{2}{*}{ tSNP ID } & \multicolumn{3}{|l|}{ Primers } & \multicolumn{3}{|c|}{ Restriction endonucleases } \\
\hline & $\begin{array}{l}\text { Primer sequences }{ }^{\mathrm{a}} \\
\qquad\left(5^{\prime}-3^{\prime}\right)\end{array}$ & $\begin{array}{c}\text { Temp } \\
\left({ }^{\circ} \mathrm{C}\right)\end{array}$ & $\begin{array}{l}\text { Product } \\
\text { length (bp) }\end{array}$ & $\begin{array}{c}\text { Restriction } \\
\text { endonucleases }\end{array}$ & $\begin{array}{l}\text { Incubate } \\
\text { temp }\left({ }^{\circ} \mathrm{C}\right)\end{array}$ & $\begin{array}{l}\text { Specific allele } \\
\quad \text { (position) }^{\mathrm{b}}\end{array}$ \\
\hline rs1404008 & $\begin{array}{l}\text { FP: ATTATTCATTGCCGCTTTAG } \\
\text { RP: TTGAATGGGTTTTAGCAATC }\end{array}$ & 53 & 156 & Taq I & 65 & $\mathrm{~T}(89)$ \\
\hline rs 1880242 & $\begin{array}{l}\text { FP: CTTCTGCACCCACAGGAAAT } \\
\text { RP: GTGTGGCCCGTTACCTCTAA }\end{array}$ & 63 & 213 & Rsa I & 37 & $\mathrm{G}(115)$ \\
\hline rs 10499563 & $\begin{array}{l}\text { FP: GCCTGGTCTGGCCTGTATAA } \\
\text { RP: CCCAAGGACCTGTTAGTGGA }\end{array}$ & 60 & 222 & Taa I & 65 & $\mathrm{C}(51)$ \\
\hline rs1800796 & $\begin{array}{l}\text { FR: TGGCAAAAAGGAGTCACACA } \\
\text { RP: CCCAAGCCTGGATTATGAAG }\end{array}$ & 62 & 162 & Mbi I & 37 & $\mathrm{G}(88)$ \\
\hline rs2069837 & $\begin{array}{l}\text { FR: CAGCCTTGTGATCTTGGGTAAAT } \\
\text { RP: GGGGCACACTTGGGTTCA }\end{array}$ & 60 & 309 & Dra I & 37 & A (177) \\
\hline
\end{tabular}

${ }^{\mathrm{a} F R}$, forward primer; RP, reverse primer. ${ }^{\mathrm{b}}$ The polymorphic alleles are identified and digested by restriction endonucleases at the specific sites of PCR products. 


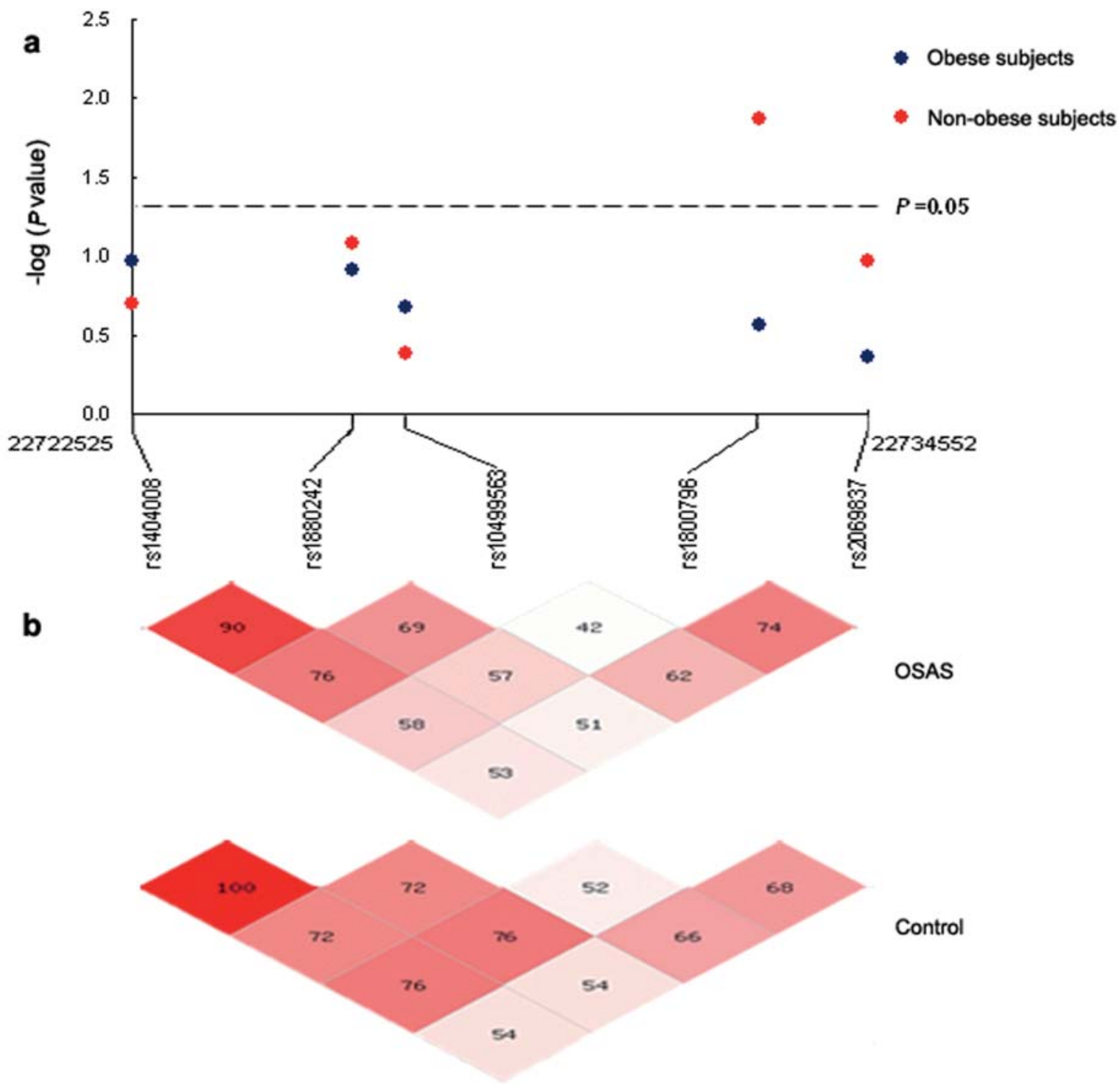

Figure 2. Significance and LD map of the five tSNPs. (a) Significance of each tSNP in two groups, including obese subjects (blue dot) and non-obese subjects (red dot). The $\mathrm{x}$-axis shows genomic position of five tSNPs and $\mathrm{y}$-axis shows the negative base-10 logarithm of the $\mathrm{p}$ values corresponding to OR values of each tSNP. The most significant tSNP, rs 1800796, was found in the non-obese group but not in obese subjects. (b) LD maps ( $\mathrm{r}^{2}$ measure) of the five tSNPs of IL-6 for OSAS cases and controls were generated by SHEsis program.

lower among non-obese OSAS patients $(19.7 \%)$ than nonobese controls $(33.9 \%, \mathrm{p}=0.014)$, indicating that non-obese individuals with $I L-6-572 \mathrm{G}$ have a decreased risk of developing OSAS (OR, 0.48, 95\% CI, 0.26-0.86). The other four tSNPs were identified as incapable of modifying susceptibility of non-obese OSAS ( $>>0.05$ ) (Table VI, Fig. 2a).

IL-6 -572G/C polymorphism, BMI and severity of sleepdisordered breathing. To analyze whether $I L-6-572 \mathrm{G} / \mathrm{C}$ polymorphism modifies the risk of obesity and severity of sleepdisordered breathing, we performed independent ANOVA tests among individuals with three genotypes ( $G G, C G$ and $C C)$. As shown in Fig. 3a, mean BMI did not present significant differences according to the individuals carrying any of the three genotypes of $I L-6-572 \mathrm{G} / \mathrm{C}$ polymorphism in both the OSAS $(p=0.661)$ and healthy control groups $(p=0.552)$, indicating that the influence of this polymorphism on OSAS developing was independent of BMI. In non-obese individuals $(n=117)$, the severity of sleep-disordered breathing (measured
Table II. Characteristics of patients with OSAS and healthy controls. ${ }^{\mathrm{a}}$

\begin{tabular}{lcrr}
\hline Characteristics & $\begin{array}{c}\text { OSAS } \\
(\mathrm{n}=151)\end{array}$ & $\begin{array}{c}\text { Controls } \\
(\mathrm{n}=75)\end{array}$ & $\mathrm{p}^{\text {-value }}$ \\
\hline Age, year & $42.5 \pm 1.0$ & $40.1 \pm 1.5$ & 0.159 \\
$\mathrm{BMI}, \mathrm{kg} / \mathrm{m}^{2}$ & $28.4 \pm 0.4$ & $25.3 \pm 0.4$ & $<0.001$ \\
$\mathrm{AHI}, \mathrm{events} / \mathrm{h}$ & $55.6 \pm 1.8$ & $6.0 \pm 0.5$ & $<0.001$ \\
$\mathrm{AI}$, events/h & $36.4 \pm 1.9$ & $1.8 \pm 0.3$ & $<0.001$ \\
$\% \mathrm{SaO}_{2}<90 \%$ & $27.4 \pm 1.8$ & $1.9 \pm 0.7$ & $<0.001$ \\
$\mathrm{Mean} \mathrm{SaO}_{2}, \%$ & $91.0 \pm 0.3$ & $95.2 \pm 0.2$ & $<0.001$ \\
Lowest $\mathrm{SaO}_{2}, \%$ & $67.7 \pm 1.0$ & $85.3 \pm 0.7$ & $<0.001$ \\
\hline
\end{tabular}

${ }^{\text {aD }}$ ata are presented as mean \pm SE. Most subjects were male. BMI, body mass index; AHI, apnea hypopnea index; AI, apnea index; \% $\mathrm{SaO}_{2}<90 \%$, percentage of total sleep time with $\mathrm{SaO}_{2}<90 \%$; ${ }^{\mathrm{b}}$ p-values were calculated by independent-samples t-test. 
Table III. BMI and the risk of OSAS.

\begin{tabular}{|c|c|c|c|c|c|c|}
\hline $\operatorname{BMI}\left(\mathrm{kg} / \mathrm{m}^{2}\right)^{\mathrm{a}}$ & Cases, n (\%) & Controls, n (\%) & OR $(95 \% \mathrm{CI})^{\mathrm{b}}$ & $\mathrm{p}$ value & OR $(95 \% \mathrm{CI})^{\mathrm{b}}$ & $\mathrm{p}$-value \\
\hline$<23$ & $7(4.6)$ & $16(21.4)$ & 1.00 & & & \\
\hline $23-27$ & $54(35.8)$ & $40(53.3)$ & $2.94(1.00-8.64)$ & 0.050 & & 1.00 \\
\hline$\geq 27$ & $90(59.6)$ & $19(25.3)$ & $9.09(3.07-26.92)$ & $<0.001$ & $3.84(2.02-7.29)$ & $<0.001$ \\
\hline
\end{tabular}

aData are presented based on the cut-off point for overweight and obesity in CHB population with a BMI of 23 and $27 \mathrm{~kg} / \mathrm{m}^{2}$, respectively; ${ }^{\mathrm{b}} \mathrm{OR}, 95 \% \mathrm{CI}$ and $\mathrm{p}$-values were from logistic regression, adjusted for age and gender.

a

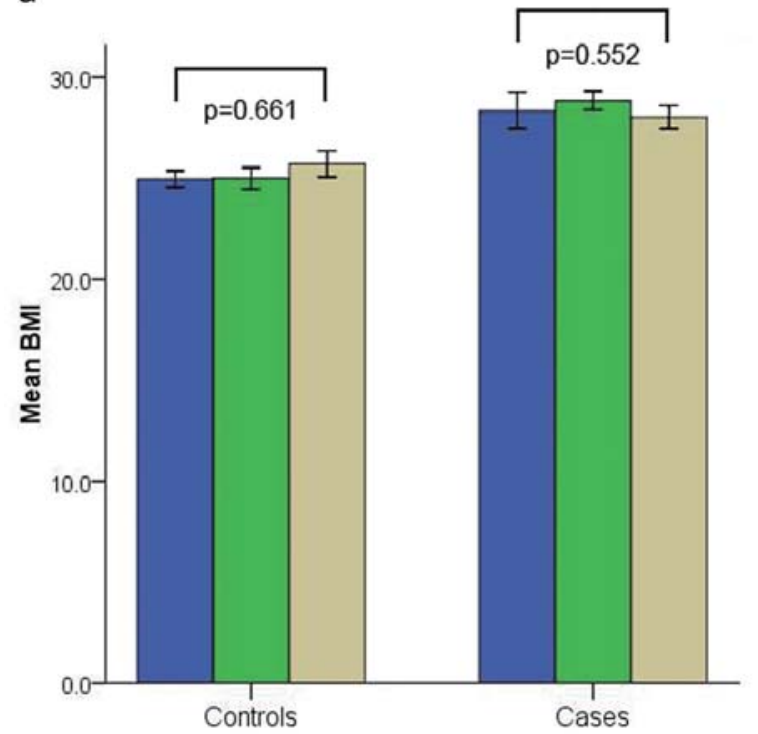

b

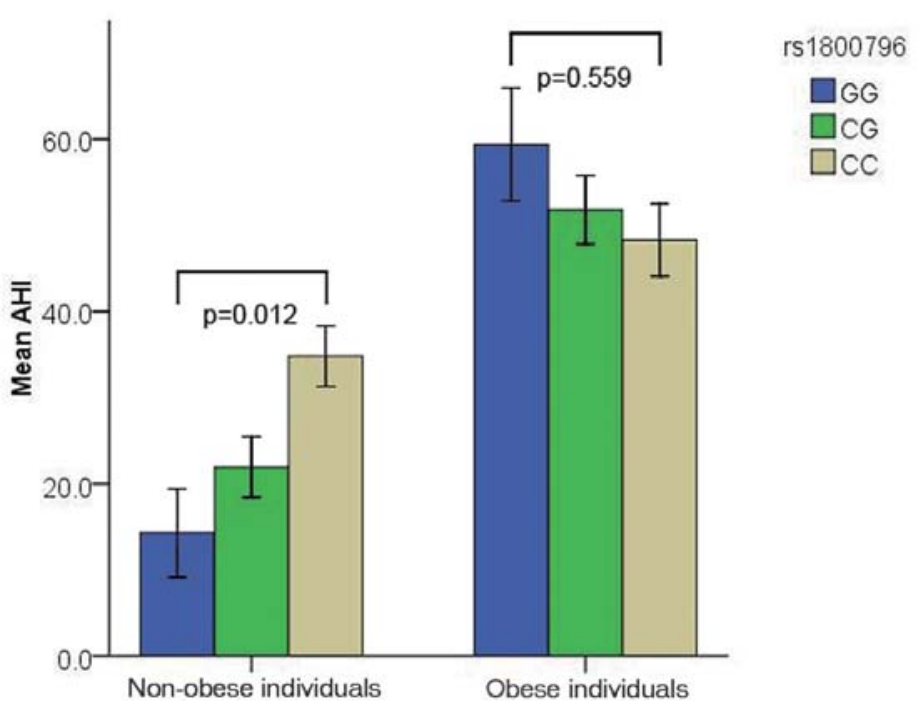

Figure 3. BMI, AHI, and genotype of $I L-6-572 \mathrm{G} / \mathrm{C}$ polymorphism. Data are presented as mean \pm SE. Bars, \pm SE. (a) Mean BMI levels with different genotypes of $I L-6-572 \mathrm{G} / \mathrm{C}$ polymorphism (rs 1800796) in OSAS patients $(28.3 \pm 0.9,28.8 \pm 0.4$ and $28.0 \pm 0.6$ for GG, CG and CC, respectively; p=0.552) and healthy controls $(25.0 \pm 0.4,25.0 \pm 0.5$ and $25.7 \pm 0.7$ for GG, CG and CC, respectively; $\mathrm{p}=0.661)$. (b) In non-obese individuals ( $\mathrm{n}=117$ ), the severity of sleepdisordered breathing (measured by AHI) increased linearly in carriers of the C variant of $I L-6-572 \mathrm{G} / \mathrm{C}$ polymorphism $(14.3 \pm 5.1,22.0 \pm 3.6$ and $34.8 \pm 3.5$ for GG, CG and CC, respectively; $\mathrm{p}=0.012)$. By contrast, in obese individuals $(\mathrm{n}=109)$, AHI did not present significantly different among individuals carrying the three genotypes $(59.4 \pm 6.6,51.8 \pm 4.0$ and $48.3 \pm 4.2$ for $\mathrm{GG}, \mathrm{CG}$ and $\mathrm{CC}$, respectively; $\mathrm{p}=0.559)$.

by $\mathrm{AHI})$ increased linearly in carriers of the $\mathrm{C}$ variant of $I L-6$ $-572 \mathrm{G} / \mathrm{C}$ polymorphism $(14.3 \pm 5.1,22.0 \pm 3.6$ and $34.8 \pm 3.5$ for GG, CG and CC, respectively; $\mathrm{p}=0.012$ ). However, there was no significant difference in severity of sleep-disordered breathing between obese individuals carrying the three genotypes $(\mathrm{n}=109, \mathrm{p}=0.559$, Fig 3b).

Haplotype analysis. Pairwise LD of the five tSNPs is shown in Fig. 2b. Two polymorphisms, rs1404008 and rs1880242, were in strong LD among OSAS patients ( $\left.D^{\prime}, 1.0 ; \mathrm{r}^{2}, 0.9\right)$ and healthy controls $\left(D^{\prime}, 1.0 ; \mathrm{r}^{2}, 1.0\right)$. Furthermore, LD between these two SNPs and the other three SNPs (rs10499563, rs1800796 and rs2069837) was extremely similar in both cases and controls. Therefore, four tSNPs (rs1880242, rs10499563, rs 1800796 and rs2069837) were selected for haplotype construction.

To assess whether various haplotypes consisting of at least two of the four tSNPs contributed to risk of OSAS, we performed OR analyses in cases and controls. As shown in Table V, when haplotypes comprising of any two of the four tSNPs were reconstructed, the frequencies for haplotype TC (rs18800242 and rs1800796) and CC (rs10499563 and rs1800796) were significantly higher in OSAS patients (5.5 and $5.4 \%$, respectively) compared with controls [(1.4\%; $\mathrm{p}=0.037 ;$ OR, 4.16;95\% CI, 0.98-17.73) and (1.5\%; $\mathrm{p}=0.049 ;$ OR, 3.74; 95\% CI, 0.92-15.21), respectively]. A more significant difference regarding the haplotypes TC and $\mathrm{CC}$ between non-obese OSAS and controls was observed [(OR, 7.92; 95\% CI, 1.02-61.70) and (OR, 7.34; 95\% CI, 1.02-52.79)]. In contrast, the haplotype TG (rs1880242, rs 1800796) had a protective effect (OR, 0.39, 95\% CI, 0.200.74), which was compatible with a hazardous effect of haplotype TC (rs18800242 and rs1800796) in non-obese OSAS. The results suggest that these three haplotypes are significantly associated with modified risk of non-obese OSAS ( $\mathrm{p}=0.020$, $\mathrm{p}=0.022$ and $\mathrm{p}=0.003$, respectively). 


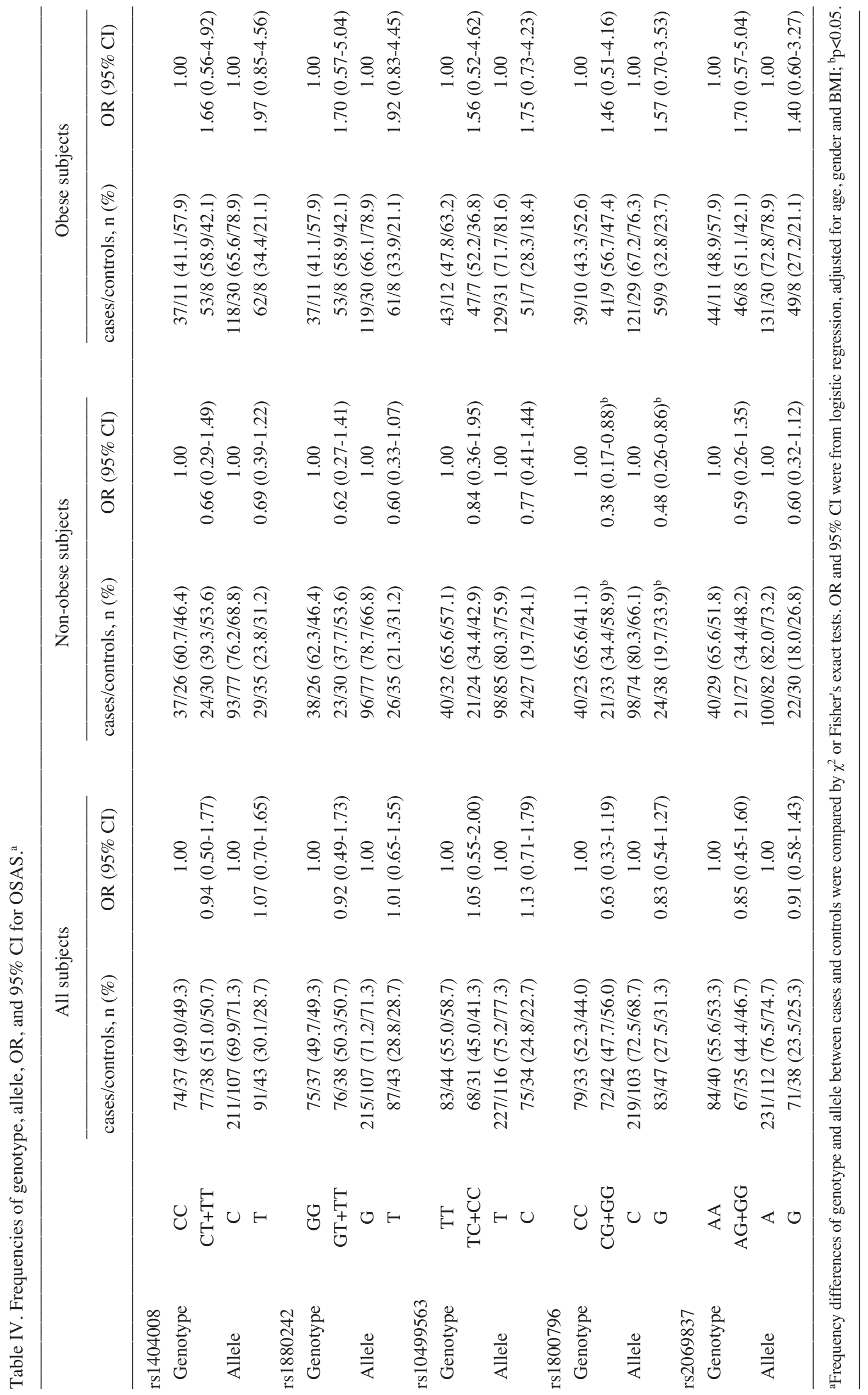


Table V. Haplotype frequencies in patients with OSAS and controls. ${ }^{a}$

\begin{tabular}{|c|c|c|c|c|c|c|}
\hline \multirow[b]{2}{*}{ Haplotype $^{b}$} & \multicolumn{2}{|c|}{ All subjects } & \multicolumn{2}{|c|}{ Non-obese subjects } & \multicolumn{2}{|c|}{ Obese subjects } \\
\hline & Frequencies $^{c}$ & OR $(95 \% \mathrm{CI})$ & Frequencies ${ }^{c}$ & OR $(95 \% \mathrm{CI})$ & Frequencies ${ }^{c}$ & OR $(95 \% \mathrm{CI})$ \\
\hline$\sim \sim \mathrm{CA}$ & $71.8 / 67.9$ & $1.21(0.79-1.85)$ & $78.6 / 66.1$ & $2.05(1.13-3.72)^{\mathrm{d}}$ & $67.2 / 73.5$ & $0.66(0.29-1.49)$ \\
\hline $\mathrm{GT} \sim \mathrm{A}$ & $67.6 / 67.8$ & $1.04(0.64-1.71)$ & $74.3 / 65.9$ & $1.93(1.01-3.66)^{\mathrm{d}}$ & $63.1 / 73.5$ & $0.65(0.29-1.48)$ \\
\hline GTCA & $66.4 / 66.6$ & $1.15(0.73-1.83)$ & $72.8 / 65.1$ & $2.31(1.19-4.51)^{\mathrm{d}}$ & $62.1 / 70.8$ & $0.58(0.22-1.50)$ \\
\hline $\mathrm{T} \sim \mathrm{G} \sim$ & $23.3 / 27.3$ & $0.81(0.52-1.27)$ & $14.4 / 30.3$ & $0.39(0.20-0.74)^{\mathrm{e}}$ & $29.3 / 18.2$ & $1.92(0.79-4.66)$ \\
\hline $\mathrm{T} \sim \mathrm{GG}$ & $19.8 / 21.6$ & $0.94(0.58-1.53)$ & $12.7 / 23.2$ & $0.50(0.25-1.00)^{\mathrm{d}}$ & $24.7 / 15.6$ & $1.79(0.69-4.65)$ \\
\hline$\sim \mathrm{CG} \sim$ & $19.4 / 21.2$ & $0.90(0.55-1.46)$ & $12.7 / 23.1$ & $0.48(0.24-0.96)^{\mathrm{d}}$ & $24.0 / 15.5$ & $1.77(0.69-4.56)$ \\
\hline TCG & $19.0 / 21.2$ & $0.86(0.57-1.51)$ & $12.1 / 23.1$ & $0.44(0.21-0.91)^{\mathrm{d}}$ & $23.7 / 15.6$ & $1.76(0.68-4.53)$ \\
\hline TCGG & $19.0 / 20.6$ & $0.90(0.54-1.56)$ & $12.1 / 22.2$ & $0.47(0.22-0.99)^{\mathrm{d}}$ & $23.7 / 15.7$ & $1.73(0.67-4.49)$ \\
\hline $\mathrm{T} \sim \mathrm{C} \sim$ & $5.5 / 1.4$ & $4.16(0.98-17.73)^{d}$ & $6.9 / 0.9$ & $7.92(1.02-61.70)^{\mathrm{d}}$ & - & - \\
\hline$\sim \mathrm{CC} \sim$ & $5.4 / 1.5$ & $3.74(0.92-15.21)^{\mathrm{d}}$ & $7.0 / 1.0$ & $7.34(1.02-52.79)^{\mathrm{d}}$ & - & - \\
\hline
\end{tabular}

a Only the common haplotypes, frequencies of $>5 \%$, in CHB and significantly different between cases and controls, were included; ${ }^{b}$ four tSNPs alleles that lined from left to right (rs1880242, rs10499563, rs1800796 and rs2069837) were used for haplotype reconstruction; chaplotype frequencies $(\%)$ in OSAS and controls; ${ }^{\mathrm{d}} 0.01<\mathrm{p}<0.05 ;{ }^{\mathrm{e}} \mathrm{p}=0.003 ; \sim$, represents variable alleles of certain specific tSNP; -, not included due to frequency $<5 \%$.

\section{Discussion}

This is the first study to provide evidence that susceptibility to OSAS is influenced by genetic variants in $I L-6$. Using a haplotype-tagging SNPs approach, we identified the $\mathrm{G}$ allele of $\mathrm{rs} 1800796(-572 \mathrm{C} / \mathrm{G})$ in the promoter region of $I L-6$ associated with reduced risk of developing non-obese OSAS, and the severity of sleep-disordered breathing increased linearly in carriers of the $\mathrm{C}$ variant of $I L-6-572 \mathrm{G} / \mathrm{C}$ polymorphism in non-obese individuals. Furthermore, our results suggest that several haplotypes play various roles in modifying the predisposition of OSAS in the Chinese population.

OSAS is now recognized as a major public health problem in the world. It increases risk of stroke and morbidity and mortality of hypertension and cardiovascular diseases (21-23). Large-scale epidemiological studies on OSAS suggest a conservatively estimated prevalence of $2-4 \%$ in middle-aged Caucasian and Chinese populations $(3,24,25)$. Preferential understanding of how OSAS develops and progresses will yield important clues to diagnosis and prevention as well as treatment for OSAS. Obesity is one of the strongest risk factors for developing OSAS $(3,4)$. Meanwhile, clinical and fundamental studies suggest that inflammation involves the pathogenesis of OSAS $(5-7,26,27)$ and IL-6 was reported to phenotypically increase in patients with OSAS (28-30). In an attempt to elucidate the relationship between genetic variants in the $I L-6$ gene and OSAS, we provided two aspects of support with a population-based study.

First, we performed an investigation on the relationship between obesity, IL- 6 and OSAS, based on the fact that overweight and obesity are strong risk factors for OSAS. The results show that being overweight or obese increases risk of OSAS more than 2- and 9-fold, respectively, compared to being normal weight. This is in accordance with previously reported data from other groups $(3,31)$. Although genetic variants that predispose obesity facilitate the development of
OSAS, polymorphisms of several obesity-related genes, including $\beta_{3}$-adrenergic receptor (ADRB3) (32), Leptin, and leptin receptor (LEPR) genes (33), are not suggested to associate with OSAS. In the present study, we found that $-572 \mathrm{G} / \mathrm{C}$ polymorphism of $I L-6$ gene is associated with OSAS susceptibility and severity of sleep-disordered breathing in non-obese subjects, suggested that SNP genotyping of IL-6 gene is a potential strategy for detecting the risk of breathing disordered diseases in non-obese individuals. Notably, the polymorphisms of the ADRB3 gene favor the development of obesity in patients who already suffer OSAS (32). However, no polymorphisms of $I L-6$ related to obesity, either in OSAS patients or healthy controls, were found in our investigation.

Wallenius et al demonstrated that IL- 6 knockout mice developed mature-onset obesity with disturbed carbo-hydrate and lipid metabolism, increased leptin levels and decreased responsiveness to leptin treatment (34), suggesting that $I L-6$ deficiency leads to obesity-related diseases. Moreover, an in vitro functional study indicated that genetic polymorphisms in the promoter influenced $I L-6$ transcription not by a simple additive mechanism, but through complex interactions determined by the haplotype (35). It is helpful to understand our findings that the haplotypes TC (rs1880242 and rs1800796) and CC (rs10499563 and rs1800796) confer increased risk of OSAS in the Chinese population.

Second, we focused on understanding whether modified risk for non-obese OSAS was attributable to genetic variants of $I L-6$. Intriguingly, $-572 \mathrm{G}$ allele of $I L-6$ significantly conferred a protective effect on OSAS in the non-obese population. A recently reported function concerning $-572 \mathrm{G}$ that reduces transcriptional activity of the IL- 6 promoter furthers our understanding of how it decreases risk of OSAS (13). More importantly, the haplotype TG (rs1880242 and rs1800796) of $I L-6$, carried by $30.3 \%$ of non-obese controls and $14.4 \%$ of cases, made a more protective contribution to OSAS than a single polymorphism $-572 \mathrm{G}$. Given that $I L-6$ down-regulates 
the synthesis of IL-1 and TNF, and play anti-inflammatory roles in several complex diseases $(9,36,37)$, the haplotype TG decreases the risk of non-obese OSAS by influencing an antiinflammation pathway in the Chinese population. Oppositely, we found that it increases the risk of OSAS, when assessing the association of this haplotype with OSAS in obese subjects (Table V). Therefore, we do not exclude the possibility that obesity diminishes the protective effect of the haplotype TG on OSAS.

However, our estimates will likely show ethnic differences and require confirmation in various types of populations. In support of this, an exemplified genetic variant, polymorphism $-174 \mathrm{G} / \mathrm{C}$ of $I L-6$ promoter (rs1800795), is prone to a wide variety of diseases in the European population (10,38-40) while it presents null heterozygous in the Chinese population. Unfortunately, no report on whether this polymorphism confers the risk of OSAS was documented in the European population.

In summary, to the best of our knowledge, this is the first study to suggest that genetic variants in $I L-6$ modify OSAS susceptibility in the Chinese population. The $-572 \mathrm{G} / \mathrm{C}$ polymorphism of the $I L-6$ gene is associated with OSAS susceptibility and severity of sleep-disordered breathing in non-obese individuals. Furthermore, several haplotypes play various roles in modifying the predisposition of OSAS in the Chinese population. Genotyping of the $I L-6$ gene is a potential strategy for detecting the risk of breathing disordered diseases in non-obese individuals.

\section{Acknowledgements}

We are grateful for participation and cooperation of the patients with OSAS. This work was supported by grants from the National Natural Science Foundation of China (30672400 to H.-T. Zhang), the Science and Technology Committee of Jiangsu Province (BK2008162 to H.-T. Zhang), SRF for ROCS, State Education Ministry (2008890 to H.-T. Zhang), Qing-Lan Project of Education Bureau of Jiangsu Province (to H.-T. Zhang) and Research Start-up Program for Young Scientists of Soochow University (to X. Zhang).

\section{References}

1. Strollo PJ Jr and Rogers RM: Obstructive sleep apnea. N Engl J Med 334: 99-104, 1996

2. Caples SM, Gami AS and Somers VK: Obstructive sleep apnea. Ann Intern Med 142: 187-197, 2005.

3. Young T, Peppard PE and Gottlieb DJ: Epidemiology of obstructive sleep apnea: a population health perspective. Am J Respir Crit Care Med 165: 1217-1239, 2002.

4. Patel SR: Shared genetic risk factors for obstructive sleep apnea and obesity. J Appl Physiol 99: 1600-1606, 2005.

5. Barcelo A, Elorza MA, Barbe F, Santos C, Mayoralas LR and Agusti AG: Angiotensin converting enzyme in patients with sleep apnoea syndrome: plasma activity and gene polymorphisms. Eur Respir J 17: 728-732, 2001

6. Riha RL, Brander P, Vennelle M, et al: Tumour necrosis factoralpha $(-308)$ gene polymorphism in obstructive sleep apnoeahypopnoea syndrome. Eur Respir J 26: 673-678, 2005.

7. Bayazit YA, Erdal ME, Yilmaz M, et al: Insulin receptor substrate gene polymorphism is associated with obstructive sleep apnea syndrome in men. Laryngoscope 116: 1962-1965, 2006.

8. Woods A, Brull DJ, Humphries SE and Montgomery HE: Genetics of inflammation and risk of coronary artery disease: the central role of interleukin-6. Eur Heart J 21: 1574-1583, 2000 .
9. Seruga B, Zhang H, Bernstein LJ and Tannock IF: Cytokines and their relationship to the symptoms and outcome of cancer. Nat Rev Cancer 8: 887-899, 2008.

10. Fishman D, Faulds G, Jeffery R, et al: The effect of novel polymorphisms in the interleukin-6 (IL-6) gene on IL-6 transcription and plasma IL-6 levels, and an association with systemic-onset juvenile chronic arthritis. J Clin Invest 102: 1369-1376, 1998.

11. Brull DJ, Montgomery HE, Sanders J, et al: Interleukin-6 gene $-174 \mathrm{~g}>\mathrm{c}$ and $-572 \mathrm{~g}>\mathrm{c}$ promoter polymorphisms are strong predictors of plasma interleukin-6 levels after coronary artery bypass surgery. Arterioscler Thromb Vasc Biol 21: 1458-1463, 2001.

12. Liu Y, Berthier-Schaad Y, Fallin MD, et al: IL-6 haplotypes, inflammation, and risk for cardiovascular disease in a multiethnic dialysis cohort. J Am Soc Nephrol 17: 863-870, 2006.

13. Gu W, Du DY, Huang J, et al: Identification of interleukin-6 promoter polymorphisms in the Chinese Han population and their functional significance. Crit Care Med 36: 1437-1443, 2008.

14. Smith AJ, D'Aiuto F, Palmen J, et al: Association of serum interleukin-6 concentration with a functional IL6 -6331T>C polymorphism. Clin Chem 54: 841-850, 2008.

15. Klipstein-Grobusch K, Mohlig M, Spranger J, et al: Interleukin-6 g.-174G $>$ C promoter polymorphism is associated with obesity in the EPIC-Potsdam Study[ast]. Obesity 14: 14-18, 2006.

16. Goyenechea E, Parra D and Martinez JA: Impact of interleukin 6 $-174 \mathrm{G}>\mathrm{C}$ polymorphism on obesity-related metabolic disorders in people with excess in body weight. Metabolism 56: 1643-1648, 2007.

17. Akey J, Jin L and Xiong M: Haplotypes vs single marker linkage disequilibrium tests: what do we gain? Eur J Hum Genet 9: 291-300, 2001 .

18. Akashiba T, Akahoshi T, Kawahara S, et al: Clinical characteristics of obesity-hypoventilation syndrome in Japan: a multi-center study. Intern Med 45: 1121-1125, 2006.

19. Liu Z, Zhao J, Chen XF, et al: CpG island methylator phenotype involving tumor suppressor genes located on chromosome $3 \mathrm{p}$ in non-small cell lung cancer. Lung Cancer 62: 15-22, 2008.

20. Shi YY and He L: SHEsis, a powerful software platform for analyses of linkage disequilibrium, haplotype construction, and genetic association at polymorphism loci. Cell Res 15: 97-98, 2005.

21. Yaggi HK, Concato J, Kernan WN, Lichtman JH, Brass LM and Mohsenin V: Obstructive sleep apnea as a risk factor for stroke and death. N Engl J Med 353: 2034-2041, 2005.

22. Shamsuzzaman AS, Gersh BJ and Somers VK: Obstructive sleep apnea: implications for cardiac and vascular disease. JAMA 290: 1906-1914, 2003.

23. Gozal D and Kheirandish-Gozal L: Cardiovascular morbidity in obstructive sleep apnea: oxidative stress, inflammation, and much more. Am J Respir Crit Care Med 177: 369-375, 2008.

24. Ip MS, Lam B, Lauder IJ, et al: A community study of sleepdisordered breathing in middle-aged Chinese men in Hong Kong. Chest 119: 62-69, 2001.

25. Ip MS, Lam B, Tang LC, Lauder IJ, Ip TY and Lam WK: A community study of sleep-disordered breathing in middle-aged Chinese women in Hong Kong: prevalence and gender differences. Chest 125: 127-134, 2004.

26. Gozal D, Serpero LD, Sans Capdevila O and Kheirandish-Gozal L: Systemic inflammation in non-obese children with obstructive sleep apnea. Sleep Med 9: 254-259, 2008.

27. Jelic S, Padeletti M, Kawut SM, et al: Inflammation, oxidative stress, and repair capacity of the vascular endothelium in obstructive sleep apnea. Circulation 117: 2270-2278, 2008.

28. Yokoe T, Minoguchi K, Matsuo H, et al: Elevated levels of C-reactive protein and interleukin-6 in patients with obstructive sleep apnea syndrome are decreased by nasal continuous positive airway pressure. Circulation 107: 1129-1134, 2003.

29. Carpagnano GE, Kharitonov SA, Resta O, Foschino-Barbaro MP, Gramiccioni E and Barnes PJ: Increased 8-isoprostane and interleukin-6 in breath condensate of obstructive sleep apnea patients. Chest 122: 1162-1167, 2002.

30. Imagawa S, Yamaguchi Y, Ogawa K, et al: Interleukin-6 and tumor necrosis factor-alpha in patients with obstructive sleep apnea-hypopnea syndrome. Respiration 71: 24-29, 2004.

31. Peppard PE, Young T, Palta M, Dempsey J and Skatrud J: Longitudinal study of moderate weight change and sleepdisordered breathing. JAMA 284: 3015-3021, 2000.

32. Pierola J, Barcelo A, de la Pena M, et al: beta3-Adrenergic receptor Trp64Arg polymorphism and increased body mass index in sleep apnoea. Eur Respir J 30: 743-747, 2007. 
33. Hanaoka M, Yu X, Urushihata K, Ota M, Fujimoto K and Kubo K: Leptin and leptin receptor gene polymorphisms in obstructive sleep apnea syndrome. Chest 133: 79-85, 2008

34. Wallenius V, Wallenius K, Ahren B, et al: Interleukin-6-deficient mice develop mature-onset obesity. Nat Med 8: 75-79, 2002.

35. Terry CF, Loukaci V and Green FR: Cooperative influence of genetic polymorphisms on interleukin 6 transcriptional regulation. J Biol Chem 275: 18138-18144, 2000.

36. Libert C, Takahashi N, Cauwels A, Brouckaert P, Bluethmann H and Fiers W: Response of interleukin-6-deficient mice to tumor necrosis factor-induced metabolic changes and lethality. Eur J Immunol 24: 2237-2242, 1994

37. Cuzzocrea S, Mazzon E, Dugo L, et al: Absence of endogenous interleukin-6 enhances the inflammatory response during acute pancreatitis induced by cerulein in mice. Cytokine 18: 274-285, 2002 .
38. Humphries SE, Luong LA, Ogg MS, Hawe E and Miller GJ: The interleukin- $6-174 \mathrm{G} / \mathrm{C}$ promoter polymorphism is associated with risk of coronary heart disease and systolic blood pressure in healthy men. Eur Heart J 22: 2243-2252, 2001

39. Gaudino M, Andreotti F, Zamparelli R, et al: The $-174 \mathrm{G} / \mathrm{C}$ interleukin-6 polymorphism influences postoperative interleukin-6 levels and postoperative atrial fibrillation. Is atrial fibrillation an inflammatory complication? Circulation 108 (Suppl 1): 195-199, 2003.

40. Mayosi BM, Avery PJ, Baker M, et al: Genotype at the $-174 \mathrm{G} / \mathrm{C}$ polymorphism of the interleukin- 6 gene is associated with common carotid artery intimal-medial thickness: family study and meta-analysis. Stroke 36: 2215-2219, 2005. 